\title{
Initial endoscopic intervention is not associated with reduced risk of recurrent gastrointestinal bleeding in left ventricular assist device patients
}

\author{
Benjamin Sterna, Parth Maheshwarib, Venkata S. Gorrepati ${ }^{a}$, Deborah Bethards ${ }^{a}$, \\ Jayakrishna Chintanaboinac, John Boehmer ${ }^{d}$, Kofi Clarke ${ }^{a}$ \\ Penn State Health Milton S. Hershey Medical Center, Hershey, PA; University of California San Francisco Fresno, \\ Fresno, CA, USA
}

Abstract

Background Left ventricular assist devices (LVADs) are increasingly used for mechanical support
of end-stage heart failure. Gastrointestinal bleeding (GIB) confers a significant morbidity in
LVAD patients, with rates of up to $30 \%$ at 5 years. We assessed predictors of index and recurrent
GIB (rGIB) in LVAD patients to risk stratify patients and evaluate if endoscopic approach and
intervention at index GIB impacted rGIB.

Methods A retrospective chart review of all LVAD patients at our institution from 01/01/2006 to 31/10/2016 was completed. Predictors for index and recurrent GIB were analyzed. Multivariate logistic regression analysis was created using only statistically significant dependent variables and adjusted for demographic variables.

Results A total of 77/214 (36\%) patients developed GIB, and 38/214 (17.8\%) developed rGIB. Destination therapy $(\mathrm{P}=0.01)$, longer duration of LVAD $(\mathrm{P}=0.03)$, and low albumin $(<3.5 \mathrm{~g} / \mathrm{dL})$ $(\mathrm{P}<0.001)$ were associated with increased risk of index GIB. Charlson Comorbidity Index, heart failure etiology, and Medicare were predictors of index GIB on univariate analysis, but this was not seen on multivariate analysis. Performing an endoscopy with/without intervention, non- angioectasia lesions, and location of bleeding were not statistically significant predictors of rGIB. Longer duration of hospitalization appeared to be protective for rGIB on univariate analysis.

Conclusions Index endoscopy and intervention is not associated with reduced risk of rGIB in LVAD patients. Several independent factors are associated with the risk of index GIB. Albumin is a potentially modifiable risk factor, and likely contributes to bleeding through poor nutrition. It is a surrogate marker for systemic illness, and may have pharmacologic implications.

Keywords Left ventricular assist device, gastrointestinal bleeding, endoscopy, angioectasia

Ann Gastroenterol 2021; 34 (1): 1-9

a'Division of Gastroenterology and Hepatology, Penn State Health Milton S. Hershey Medical Center, Hershey, PA, USA (Benjamin Stern, Venkata S. Gorrepati, Deborah Bethards, Kofi Clarke);

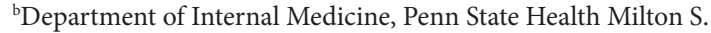
Hershey Medical Center, Hershey, PA, USA (Parth Maheshwari); 'Division of Gastroenterology, University of California San Francisco Fresno, Fresno, CA, USA (Jayakrishna Chintanaboina); ${ }^{\mathrm{d} D i v i s i o n}$ of Cardiology, Penn State Health Milton S. Hershey Medical Center, Hershey, PA, USA (John Boehmer)

Conflict of Interest: Dr Clarke has no relevant disclosures related to this project

Correspondence to: Benjamin Stern, DO, 200 Campus Dr Suite 2400, Entrance 4, Hershey, PA 17033, USA,

e-mail: bstern@pennstatehealth.psu.edu

Received 23 June 2020; accepted 23 September 2020; published online 12 July 2021

DOI: https://doi.org/10.20524/aog.2021.0656

\section{Introduction}

Heart failure (HF) affects over 6 million Americans and is associated with significant morbidity and mortality [1]. Surgical implantation of a mechanical pump, such as left ventricular assist device (LVAD) has become an increasingly common management option for end-stage HF. LVADs are used as either a bridge to transplant (BTT), or as destination therapy (DT) in patients not eligible for heart transplantation. As the number of HF patients continues to rise in parallel with an increase in indications for LVADs as destination therapy, the number of LVAD implantations has increased [2]. Gastrointestinal (GI) bleeding (GIB) remains the most common adverse event within this large population of patients, with bleeding rates up to $30 \%$ at 5 years [3-5]. GIB in LVAD patients does not appear associated with an increase 
in overall mortality but confers a significant morbidity and remains challenging to manage [6].

Although GIB after initial hospitalization for LVAD implantation has been described along the entire GI tract, the optimal endoscopic approach to management is unclear [7-12]. LVAD patients have high incidence of arteriovenous malformation (AVM) or angioectatic bleeds $(\sim 50 \%)$ when a lesion is identified [13-15]. This is likely due to Heyde syndrome-type pathophysiology with cleavage of von Willebrand factor (vWF) as well as mucosal hypoxia and dysregulation of angiogenesis $[13,16]$. Up to $30 \%$ of these lesions are located in the small bowel (SB) which may be difficult to treat endoscopically and furthermore the lesions tend to recur [14,17]. This is an area of extensive and ongoing research. Several prior manuscripts have suggested a tailored algorithmic approach to this unique patient population, although the benefit of endoscopy in this population is unclear $[10,18]$. While video capsule endoscopy (VCE) appears safe in LVAD patients, a positive or negative VCE or any subsequent endoscopic intervention do not appear to decrease the rate of recurrent GIB (rGIB) [19]. The average cost of a traditional endoscopic workup of these patients is approximately $\$ 9,000$ per event, is cumbersome to patients, and places a burden on the healthcare system [20].

We performed a comprehensive evaluation and characterization of predictors of index GIB and rGIB in LVAD patients. The primary goal was to identify predictors that help risk stratify patients and help guide informed consent pre-LVAD implantation for GIB. The secondary goal was to evaluate if endoscopic approach and/or treatment during index GIB impacts the risk of rGIB. In addition, we describe our experience with octreotide.

\section{Patients and methods}

\section{Baseline data and definitions}

An electronic medical record (EMR) chart review was completed on all patients with an LVAD device placed at a single academic tertiary-care center and documented in an institutional registry from $1^{\text {st }}$ January 2006 to $31^{\text {st }}$ October 2016. Institutional Review Board approval from Penn State University was obtained. All patients with LVADs aged $\geq 18$ years old were included. Patients with incomplete data or total-artificial heart were excluded from the study. Data collected included demographics: age, date of death, sex, body mass index (characterized as underweight, normal, overweight, obese), insurance type (Medicare, Medicaid, self-pay, or private insurance), and smoking status (former, current, never). Other baseline data collected included etiology of HF (ischemic vs. non-ischemic), LVAD intent (BTT vs. DT), and history of GIB prior to LVAD implantation.

GIB (index or rGIB) was defined as hospitalization for anemia not attributed to another cause. All patients had at least $1 \mathrm{~g} / \mathrm{dL}$ decrease in hemoglobin. Baseline laboratory data was obtained from routine post-LVAD implantation outpatient visit laboratory data (typically 3-6 months postoperation). At our institution, all patients are anticoagulated post-operatively with at least warfarin with an initial goal therapeutic international normalized ratio (INR) of 2.0-3.0. Other medications, medical and/or endoscopic management determined by managing clinicians were recorded. All patients were admitted to cardiology division with gastroenterological consultation and the ability to perform bedside endoscopy.

\section{Index GIB}

Data documented at the time of index GIB included LVAD parameters (flow, speed, power, pulsatility index [only recorded for HeartMate ${ }^{\mathrm{TM}}$ devices]), duration of LVAD (months), LVAD device type (HeartMate $\mathrm{II}^{\mathrm{TM}}$, HeartMate $\mathrm{III}^{\mathrm{TM}}$, HeartMate $\mathrm{XVE}^{\mathrm{TM}}$, HeartWare ${ }^{\mathrm{TM}}$, and "other" which included PierceDonachy VAD ${ }^{\mathrm{TM}}$ and Thoratec VAD ${ }^{\mathrm{TM}}$ ), calculated Charlson Comorbidity Index (CCI) [22], echocardiogram findings (ejection fraction $[\mathrm{EF}]$ and right ventricular $[\mathrm{RV}]$ dysfunction [none, mild, moderate, severe]), presenting symptom (hematemesis, melena, hematochezia, "mixed" [e.g., maroon] stool, coffee-ground emesis, or hemoccult), number of packed red blood cells ( $\mathrm{pRBC}$ ) transfused, anticoagulation prior to index GIB (warfarin, aspirin, anti-platelet(s), and/or other anti-coagulant(s)), goal therapeutic INR (1.5-2.0, 2.0-2.5, 2.0$3.0,2.5-3.5,1.5-2.5$, other, or $\mathrm{n} / \mathrm{a}$ ), change to anticoagulation (no change, discontinued anticoagulant/anti-platelet, decreased goal therapeutic INR), other medication use (proton pump inhibitor [PPI] and non-steroidal anti-inflammatory drugs [NSAID]), day(s) to endoscopy, and number of days hospitalized. Labs at index bleeding recorded included serum creatinine, platelet level, albumin, blood urea nitrogen, INR, hemoglobin, and bilirubin.

\section{Endoscopy and rGIB}

Endoscopic data collected during index and rGIB included location of bleeding (esophageal, gastric, proximal third of $\mathrm{SB}$, middle third of $\mathrm{SB}$, distal third of $\mathrm{SB}$, colon, unknown), endoscopic approach (esophagogastric duodenoscopy [EGD], colonoscopy, EGD and colonoscopy, VCE \pm other, push enteroscopy \pm other, double-balloon enteroscopy \pm other, none), lesion characteristic (ulcer, angioectasia, malignancy, other, unknown), endoscopic intervention (epinephrine injection, cauterization, hemostatic clip(s), dual therapy, none), failed endoscopy (including interventional radiology and/or surgery), days hospitalized for rGIB, and time to rGIB (months). Endoscopic approach included all endoscopic procedures completed during the course of a GIB (or rGIB) hospitalization and lesion characteristic was the first discovered lesion during that hospitalization. 


\section{Statistical analysis}

Univariate analysis was performed using all the abovementioned predictors for index GIB and rGIB. For the purpose of comparison, Student's $t$-test was used for continuous variables and chi-square for categorical variables. Multivariate logistic regression analysis was performed using statistically significant variables while adjusting for the demographic variables. All analyses were performed using SAS version 9.4 software (SAS Institute, Cary, NC); a P-value $\leq 0.05$ was considered statistically significant.

\section{Results}

Demographic and other characteristics of patients with and without GIB are displayed in Table 1. Seventy-seven of $214(36.0 \%)$ patients in our cohort experienced at least 1 episode of GIB (index GIB). Actuarial freedom from a GIB while censoring for transplant, explant or death was calculated and the incidence of GIB at 1 year was $27 \%$, and then levels off thereafter (Fig. 1). On univariate analysis, destination therapy, Medicare insurance, longer duration of LVAD, ischemic cardiomyopathy, CCI, and albumin were significantly different in patients with and without GIB. The mean duration of LVAD for patients with GIB was 28.14 months vs. 18.12 for those without GIB $(\mathrm{P}<0.01)$. Comparing patients with and without GIB postLVAD implantation, they appeared similar in terms of age distribution, sex, obesity, LVAD device type, LVAD parameters, goal therapeutic INR, anticoagulant use, history of GIB, echocardiogram findings, and medications (PPI or NSAID use).

On multivariate analysis, LVAD as destination therapy (odds ratio [OR] 3.04, 95\% confidence interval [CI] 1.3-7.0;
$\mathrm{P}=0.01$ ), longer duration of LVAD (OR 1.02, 95\%CI 1.0021.040; $\mathrm{P}=0.03)$, and low albumin $(<3.5 \mathrm{~g} / \mathrm{dL})(\mathrm{OR} 5.11,95 \% \mathrm{CI}$ 2.4-10.7; $\mathrm{P}<0.001$ ) were found to be associated with increased risk of index GIB (Table 2).

rGIB occurred in 38 patients (17.8\% of all patients, $49.4 \%$ of index GIB patients). A second rGIB occurred in 19 patients ( $8.9 \%$ of all patients, $24.7 \%$ of index GIB patients), and a third rGIB in 11 patients $(5.1 \%$ of all patients, and $14.3 \%$ of index GIB patients). Descriptive data including GIB location, lesion characteristic, endoscopic approach, and endoscopic intervention are shown in Table 3. The most common location for first, second, and third rGIB was "unknown", endoscopic approach was EGD, and endoscopic intervention was "none". The most common lesion on index and first rGIB was an angioectasia. The most common lesion was ulcer on second rGIB and "unknown" on the third rGIB.

To better define predictors for first rGIB (second GIB event) a multivariate logistic regression analysis was performed. There were no statistically significant variables that influenced the occurrence of first rGIB. These include performing an endoscopy, performing an intervention during endoscopy, having a non-angioectasia lesion, location of bleeding, change to anticoagulation, duration of hospitalization, use of PPI, and presenting symptom. Longer duration of hospitalization appeared protective for rGIB on univariate analysis (Table 4).

Survival was compared between the GIB group and control group over a 5-year period of time, censoring for explant or heart transplant. The GIB group and controls were compared on univariate analysis and any potential survival advantage for GIB group eventually matches the control group after 3 years (Figure 2).

During the last 3 years of the study period, octreotide was used to medically manage 4 patients with recurrent refractory

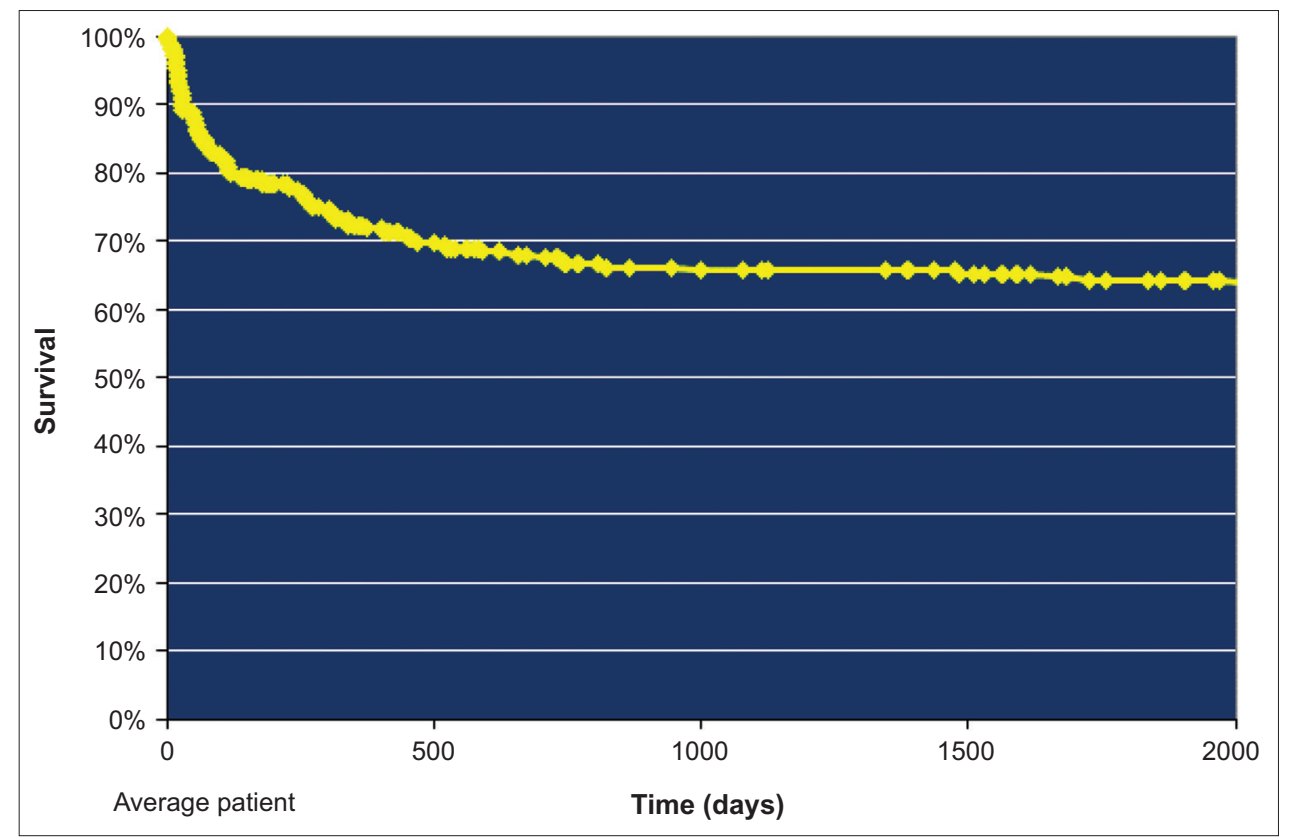

Figure 1 Actuarial survival from gastrointestinal bleeding 
Table 1 Characteristics of study population vs. controls

\begin{tabular}{|c|c|c|c|}
\hline Variable & $\begin{array}{c}\text { With GIB ( } \mathrm{n}=77) \\
\text { Number (percentage) }\end{array}$ & $\begin{array}{l}\text { Without GIB ( } \mathrm{n}=137) \\
\text { Number (percentage) }\end{array}$ & P-value \\
\hline Age (mean) & 60.64 & 58.01 & 0.061 \\
\hline LVAD intent (DT) & $59(77 \%)$ & $67(49 \%)$ & $<0.001$ \\
\hline Sex (male) & $60(78 \%)$ & $115(84 \%)$ & 0.27 \\
\hline Obese (BMI $\geq 30 \mathrm{~kg} / \mathrm{m}^{2}$ ) & $25(32 \%)$ & $37(27 \%)$ & 0.39 \\
\hline $\begin{array}{l}\text { Insurance type } \\
\text { Private } \\
\text { Medicare } \\
\text { Medicaid } \\
\text { None }\end{array}$ & $\begin{array}{c}26(34 \%) \\
43(56 \%) \\
3(4 \%) \\
5(6 \%)\end{array}$ & $\begin{array}{c}61(45 \%) \\
56(41 \%) \\
9(7 \%) \\
10(7 \%)\end{array}$ & $\begin{array}{l}0.12 \\
0.04 \\
0.41 \\
0.83\end{array}$ \\
\hline $\begin{array}{l}\text { Duration of LVAD } \\
\text { (mean months) }\end{array}$ & 28.14 & 18.12 & $<0.01$ \\
\hline Heart failure etiology (ischemic) & $56(73 \%)$ & $79(58 \%)$ & 0.03 \\
\hline $\begin{array}{l}\text { LVAD type } \\
\text { HeartMate II }{ }^{\mathrm{TM}} \\
\text { HeartWare }^{\mathrm{TM}} \\
\text { HeartMate III' } \\
\text { HeartMate XVE } \\
\text { Other }\end{array}$ & $\begin{array}{c}54(70 \%) \\
17(22 \%) \\
2(3 \%) \\
0 \\
4(5 \%)\end{array}$ & $\begin{array}{c}86(63 \%) \\
37(27 \%) \\
3(2 \%) \\
4(3 \%) \\
6(4 \%)\end{array}$ & $\begin{array}{c}0.43 \\
0.43 \\
0.85 \\
- \\
0.79\end{array}$ \\
\hline CCI (mean) & 4.21 & 3.53 & 0.01 \\
\hline History of GIB prior to LVAD & $4(5 \%)$ & $14(10 \%)$ & 0.20 \\
\hline Left ventricular EF (mean) & 22.06 & 21.49 & 0.60 \\
\hline RV dysfunction (none) & $35(46 \%)$ & $69(50 \%)$ & 0.88 \\
\hline $\begin{array}{l}\text { LVAD parameters (mean) } \\
\text { Speed (rpm) } \\
\text { Flow (L/min) } \\
\text { Power }(\mathrm{W}) \\
\text { Pulsatility index }\end{array}$ & $\begin{array}{c}7717.3 \\
5.47 \\
6.18 \\
5.05\end{array}$ & $\begin{array}{c}7523.9 \\
5.36 \\
6.01 \\
4.85\end{array}$ & $\begin{array}{l}0.68 \\
0.48 \\
0.42 \\
0.36\end{array}$ \\
\hline $\begin{array}{l}\text { Medications } \\
\text { Warfarin alone } \\
\text { ASA } \\
\text { Warfarin and ASA } \\
\text { Other }\end{array}$ & $\begin{array}{c}2(3 \%) \\
2(3 \%) \\
60(78 \%) \\
13(16 \%)\end{array}$ & $\begin{array}{c}4(3 \%) \\
9(7 \%) \\
109(80 \%) \\
15(10 \%)\end{array}$ & $\begin{array}{l}0.89 \\
0.21 \\
0.78 \\
0.22\end{array}$ \\
\hline $\begin{array}{l}\text { Goal Therapeutic INR } \\
\text { INR 1.5-2.0 } \\
\text { INR 2.0-2.5 } \\
\text { INR 2.0-3.0 } \\
\text { INR 2.5-3.5 } \\
\text { INR 1.5-2.5 } \\
\text { Other }\end{array}$ & $\begin{array}{c}12(16 \%) \\
18(23 \%) \\
28(36 \%) \\
3(4 \%) \\
3(4 \%) \\
13(17 \%)\end{array}$ & $\begin{array}{c}17(12 \%) \\
30(22 \%) \\
59(43 \%) \\
3(2 \%) \\
5(4 \%) \\
23(17 \%)\end{array}$ & $\begin{array}{l}0.51 \\
0.80 \\
0.34 \\
0.47 \\
0.93 \\
0.98\end{array}$ \\
\hline $\begin{array}{l}\text { Laboratory (mean) } \\
\text { Creatinine }(\mathrm{mg} / \mathrm{dL}) \\
\text { Platelet }\left(10^{3} / \mu \mathrm{L}\right) \\
\text { Albumin }(\mathrm{g} / \mathrm{dL}) \\
\text { Total bilirubin }(\mathrm{mg} / \mathrm{dL})\end{array}$ & $\begin{array}{c}1.42 \\
219.9 \\
3.13 \\
0.98\end{array}$ & $\begin{array}{l}1.27 \\
229 \\
3.97 \\
0.91\end{array}$ & $\begin{array}{c}0.16 \\
0.52 \\
<0.01 \\
0.52\end{array}$ \\
\hline
\end{tabular}

DT, destination therapy; BMI, body mass index; LVAD, left ventricular assist device; CCI, Charlson comorbidity index; GIB, gastrointestinal bleeding; EF, ejection fraction; $R V$, right ventricle; ASA, aspirin; INR, international normalized ratio

GIB (Table 5). All 4 patients received octreotide $100 \mu \mathrm{g}$ sub-Q b.i.d. for 4 weeks followed by $20 \mathrm{mg}$ intra-muscularly every 4 weeks thereafter. All 4 patients were initially on aspirin $81 \mathrm{mg}$ daily and warfarin with a therapeutic INR of 2.0-3.0. No other anti-platelet or anti-coagulant use was noted. These patients are included in the above data but had on average 6.5 GIB episodes prior to initiation of octreotide and required at a minimum EGD, colonoscopy, and VCE. 


\section{Discussion}

GIB remains a major comorbidity in LVAD patients. More recently, management of GIB in this patient cohort has trended towards prevention and mitigation, with proper patient selection/education as well as post-operative

Table 2 Predictors of index GIB on multivariate analysis

\begin{tabular}{lcccc}
\hline Effect & $\begin{array}{c}\text { Odds } \\
\text { ratio }\end{array}$ & \multicolumn{2}{c}{$\begin{array}{c}\text { Confidence interval } \\
\end{array}$} & P-value \\
\hline Destination Therapy & 3.038 & 1.314 & 7.023 & 0.01 \\
\hline $\begin{array}{l}\text { Duration of LVAD (per } \\
\text { month) }\end{array}$ & 1.021 & 1.002 & 1.040 & 0.03 \\
\hline Age & 0.990 & 0.956 & 1.025 & 0.56 \\
\hline Sex (male) & 1.779 & 0.718 & 4.405 & 0.21 \\
\hline $\begin{array}{l}\text { Non-smoking status } \\
\text { Obesity (BMI } \geq\end{array}$ & 0.557 & 0.144 & 2.150 & 0.53 \\
$\begin{array}{l}\text { 30 kg/m }{ }^{2} \text { ) } \\
\text { Albumin }<3.5 \text { g/dL }\end{array}$ & 0.955 & 0.471 & 1.938 & 0.90 \\
\hline $\begin{array}{l}\text { GIB, gastrointestinal bleeding; LVAD, left ventricular } \\
\text { mass index }\end{array}$ & 5.106 & 2.437 & 10.702 & $<0.01$ \\
\hline
\end{tabular}

medical management. Several studies and one meta-analysis evaluated the predictors of GIB in these patients with variable results [23-25]. A personalized GIB risk estimate score (Utah Score) has been purposed using independent risk factors for GIB in LVAD patients, although this has not been externally validated [26].

Our sample size is similar to other academic tertiary-care centers in prior publications. The prevalence of GIB in our population is $36 \%$ and consistent with other studies. Our study is comprehensive and evaluated the impact of over 20 variables. We determined that only destination therapy, longer duration of LVAD, and low albumin were independent predictors of index GIB. As reported in other previous studies and in our study, univariate analysis noted CCI, ischemic cardiomyopathy, and Medicare to be predictors of index GIB but when weighted against other dependent variables and adjusted for demographics these factors do not remain independently associated with index GIB. Age has been identified by others as a predictor of GIB, and trended toward statistically significance $(\mathrm{P}=0.06)$ in our study. Age is associated with other variables that tend to tract with age (i.e., destination therapy) and may be a risk factor not captured in our sample.

Table 3 Endoscopic description of index GIB and recurrent GIB

\begin{tabular}{|c|c|c|c|c|}
\hline Variable & $\begin{array}{c}\text { Index GIB } \\
(\mathrm{n}=77)\end{array}$ & $\begin{array}{l}\text { First recurrent } \\
\text { GIB }(n=38)\end{array}$ & $\begin{array}{l}\text { Second recurrent } \\
\text { GIB }(n=19)\end{array}$ & $\begin{array}{c}\text { Third recurrent } \\
\text { GIB }(\mathrm{n}=11)\end{array}$ \\
\hline \multicolumn{5}{|l|}{ Location } \\
\hline Esophagus & $5(6 \%)$ & $1(3 \%)$ & 0 & 0 \\
\hline Stomach & $17(22 \%)$ & $8(21 \%)$ & $5(26 \%)$ & $4(36 \%)$ \\
\hline 1st third of small bowel & $11(14 \%)$ & $4(11 \%)$ & 0 & 0 \\
\hline 2nd third of small bowel & $9(12 \%)$ & $3(8 \%)$ & $2(11 \%)$ & $1(9 \%)$ \\
\hline 3rd third of small bowel & $4(5 \%)$ & $3(8 \%)$ & $2(11 \%)$ & $1(9 \%)$ \\
\hline Colon & $13(17 \%)$ & $6(16 \%)$ & $5(26 \%)$ & 0 \\
\hline Unknown & $18(23 \%)$ & $13(34 \%)$ & $5(26 \%)$ & $5(45 \%)$ \\
\hline \multicolumn{5}{|l|}{ Endoscopic approach } \\
\hline EGD & $28(36 \%)$ & $8(21 \%)$ & $5(26 \%)$ & $4(36 \%)$ \\
\hline Colonoscopy & $5(6 \%)$ & $5(13 \%)$ & $4(21 \%)$ & $1(9 \%)$ \\
\hline EGD + colonoscopy & $19(25 \%)$ & $3(8 \%)$ & $3(16 \%)$ & $1(9 \%)$ \\
\hline Capsule & $14(18 \%)$ & $7(18 \%)$ & $3(16 \%)$ & $1(9 \%)$ \\
\hline Double-balloon enteroscopy & $1(1 \%)$ & $3(8 \%)$ & $1(5 \%)$ & $1(9 \%)$ \\
\hline Push enteroscopy & $5(6 \%)$ & $3(8 \%)$ & $1(5 \%)$ & 0 \\
\hline Other & $2(3 \%)$ & $3(8 \%)$ & 0 & 0 \\
\hline None & $3(4 \%)$ & $6(16 \%)$ & $2(11 \%)$ & $3(27 \%)$ \\
\hline \multicolumn{5}{|l|}{ Lesion characteristic } \\
\hline Ulcer & $16(21 \%)$ & $7(18 \%)$ & $7(37 \%)$ & $2(18 \%)$ \\
\hline AVM/angioectasia & $26(34 \%)$ & $15(39 \%)$ & $6(32 \%)$ & $4(36 \%)$ \\
\hline Malignancy & $4(5 \%)$ & 0 & 0 & 0 \\
\hline Other & $12(16 \%)$ & $3(8 \%)$ & $1(5 \%)$ & 0 \\
\hline Unknown & $19(25 \%)$ & $13(34 \%)$ & $5(26 \%)$ & $5(45 \%)$ \\
\hline \multicolumn{5}{|l|}{ Endoscopic intervention } \\
\hline Epinephrine injection & $4(5 \%)$ & 0 & 0 & 0 \\
\hline Cauterization & $13(17 \%)$ & $8(21 \%)$ & $5(26 \%)$ & $2(18 \%)$ \\
\hline Hemostatic clip & $6(8 \%)$ & $1(3 \%)$ & $2(11 \%)$ & 0 \\
\hline Dual therapy & $15(19 \%)$ & $6(16 \%)$ & $5(26 \%)$ & $4(36 \%)$ \\
\hline Failed (surgery or IR) & $3(4 \%)$ & $3(8 \%)$ & 0 & 0 \\
\hline None & $36(47 \%)$ & $18(47 \%)$ & $7(37 \%)$ & $5(45 \%)$ \\
\hline
\end{tabular}

$\overline{G I B}$, gastrointestinal bleeding; EGD, esophagogastroduodenoscopy; $A V M$, arteriovenous malformation; IR, interventional radiology 
Destination therapy likely reflects a higher burden of comorbid disease in this population. Albumin $(\mathrm{P}<0.001)$ is the one potentially modifiable risk factor for these patients.

Table 4 Predictors of rGIB on univariate analysis

\begin{tabular}{|c|c|c|c|c|}
\hline \multirow{2}{*}{$\begin{array}{l}\text { Effect } \\
\text { Age }\end{array}$} & \multirow{2}{*}{$\begin{array}{l}\text { Odds } \\
\text { ratio }\end{array}$} & \multicolumn{2}{|c|}{$\begin{array}{c}95 \% \\
\text { Confidence interval }\end{array}$} & \multirow{2}{*}{$\begin{array}{l}\text { P-value } \\
0.3667\end{array}$} \\
\hline & & 0.974 & 1.075 & \\
\hline Sex & 2.440 & 0.469 & 12.683 & 0.2889 \\
\hline Smoking status & 3.638 & 0.401 & 33.025 & 0.3619 \\
\hline $\begin{array}{l}\text { Obesity } \\
\left(\text { BMI } \geq 30 \mathrm{~kg} / \mathrm{m}^{2}\right)\end{array}$ & 0.415 & 0.139 & 1.238 & 0.1148 \\
\hline CCI & 0.882 & 0.659 & 1.179 & 0.3962 \\
\hline $\begin{array}{l}\text { Any change to } \\
\text { anticoagulation }\end{array}$ & 1.596 & 0.513 & 4.964 & 0.4192 \\
\hline $\begin{array}{l}\text { Time to first GIB } \\
\text { (months) }\end{array}$ & 0.963 & 0.921 & 1.007 & 0.0990 \\
\hline $\begin{array}{l}\text { Any endoscopic } \\
\text { intervention }\end{array}$ & 1.831 & 0.568 & 5.895 & 0.3110 \\
\hline Any endoscopy & 6.660 & 0.168 & 263.641 & 0.3124 \\
\hline $\begin{array}{l}\text { Non-angioectatic } \\
\text { lesion }\end{array}$ & 0.652 & 0.251 & 1.690 & 0.3787 \\
\hline $\begin{array}{l}\text { Duration of } \\
\text { hospitalization }\end{array}$ & 0.297 & 0.086 & 1.023 & 0.0544 \\
\hline PPI use & 6.893 & 0.553 & 85.888 & 0.1336 \\
\hline Presenting symptom & 0.231 & 0.036 & 1.487 & 0.1231 \\
\hline $\begin{array}{l}\text { Time from admission } \\
\text { to endoscopy (day(s)) }\end{array}$ & 0.990 & 0.952 & 1.030 & 0.6160 \\
\hline
\end{tabular}

Albumin likely contributes to bleeding through poor nutrition, is a surrogate marker for severe systemic illness, and may have potential pharmacologic implications. Hypoalbuminemia has been shown to be associated with GIB in other large studies as well [27]. The longer duration of LVAD in GIB group unfortunately represents a non-modifiable risk factor and may represent the unpredictable individual nature of GIB. Other studies have suggested that modification of LVAD device or parameters can alter GIB incidence, although in our study LVAD device type and LVAD parameters were not predictive of GIB [28]. Baseline anticoagulation/antiplatelet agent(s) or goal therapeutic INR were not associated with risk of GIB or rGIB between study population and controls.

rGIB developed in nearly half of patients within an index GIB group (49.4\%). Endoscopy did not reveal a source of bleeding in $23 \%$ of index GIB and $34 \%$ of $1^{\text {st }}$ rGIB patients. "Unknown" was the most common location for all rGIB. Consistent with other studies these patients display a high rate of angioectasia lesions with the majority of bleeding located in the upper GI tract [29]. No statistically significant predictor of rGIB was noted within this heterogeneous group on multivariate analysis. One possible explanation for ulcers being the most common lesion on second rGIB rather than angioectasia could be explained by peptic ulcer disease from recurrent hospitalizations or iatrogenic from repeated endoscopic interventions. Changes to anticoagulation/ antiplatelet agent(s) and changes to goal therapeutic INR were not associated with rGIB. This again emphasizes the challenges with non-modifiable risk factors in this particularly morbid population.

An important observation in our study is that endoscopic management was not associated with a decreased incidence of rGIB. Performing an endoscopy with/without intervention,

Table 5 Use of octreotide for refractory recurrent GIB

\begin{tabular}{|c|c|c|c|c|}
\hline Variable & Patient A & Patient B & Patient C & Patient D \\
\hline Sex & Male & Female & Male & Male \\
\hline Age at first bleeding & 74 & 61 & 53 & 68 \\
\hline LVAD indication & $\begin{array}{l}\text { Ischemic } \\
\text { cardiomyopathy }\end{array}$ & $\begin{array}{l}\text { Ischemic } \\
\text { cardiomyopathy }\end{array}$ & $\begin{array}{l}\text { Ischemic } \\
\text { cardiomyopathy }\end{array}$ & $\begin{array}{l}\text { Non-ischemic } \\
\text { cardiomyopathy }\end{array}$ \\
\hline LVAD device type & HeartMate $\mathrm{II}^{\mathrm{TM}}$ & HeartMate $\mathrm{II}^{\mathrm{TM}}$ & HeartWare ${ }^{\mathrm{TM}}$ & HeartMate $\mathrm{II}^{\mathrm{TM}}$ \\
\hline LVAD intent & Destination therapy & Destination therapy & Destination therapy & Destination therapy \\
\hline $\begin{array}{l}\text { GIB episode in which therapeutic INR was } \\
\text { decreased to } 1.5-2.0\end{array}$ & 1 st & 1 st & $3 r d$ & 2nd \\
\hline $\begin{array}{l}\text { GIB episode in which aspirin was } \\
\text { discontinued }\end{array}$ & 2nd & 4 th & 2nd & 2nd \\
\hline $\begin{array}{l}\text { Number of GIB prior to initiation of } \\
\text { octreotide }\end{array}$ & 7 over 11 months & 7 over 17 months & 6 over 37 months & $\begin{array}{l}6 \text { over } 8 \\
\text { months }\end{array}$ \\
\hline $\begin{array}{l}\text { Average time to GIB prior to initiation of } \\
\text { octreotide }\end{array}$ & 1.57 month & 2.43 months & 6.16 months & 1.33 month \\
\hline Number of GIB post-octreotide & 2 over 18 months & 2 over 24 months & $\begin{array}{l}2 \text { over } 3 \\
\text { months }\end{array}$ & 6 over 23 months \\
\hline Average time to GIB post-octreotide & 9 months & 12 months & 1.5 month & 3.83 months \\
\hline
\end{tabular}

GIB, gastrointestinal bleeding; LVAD, left ventricular assist device; INR, international normalized ratio 


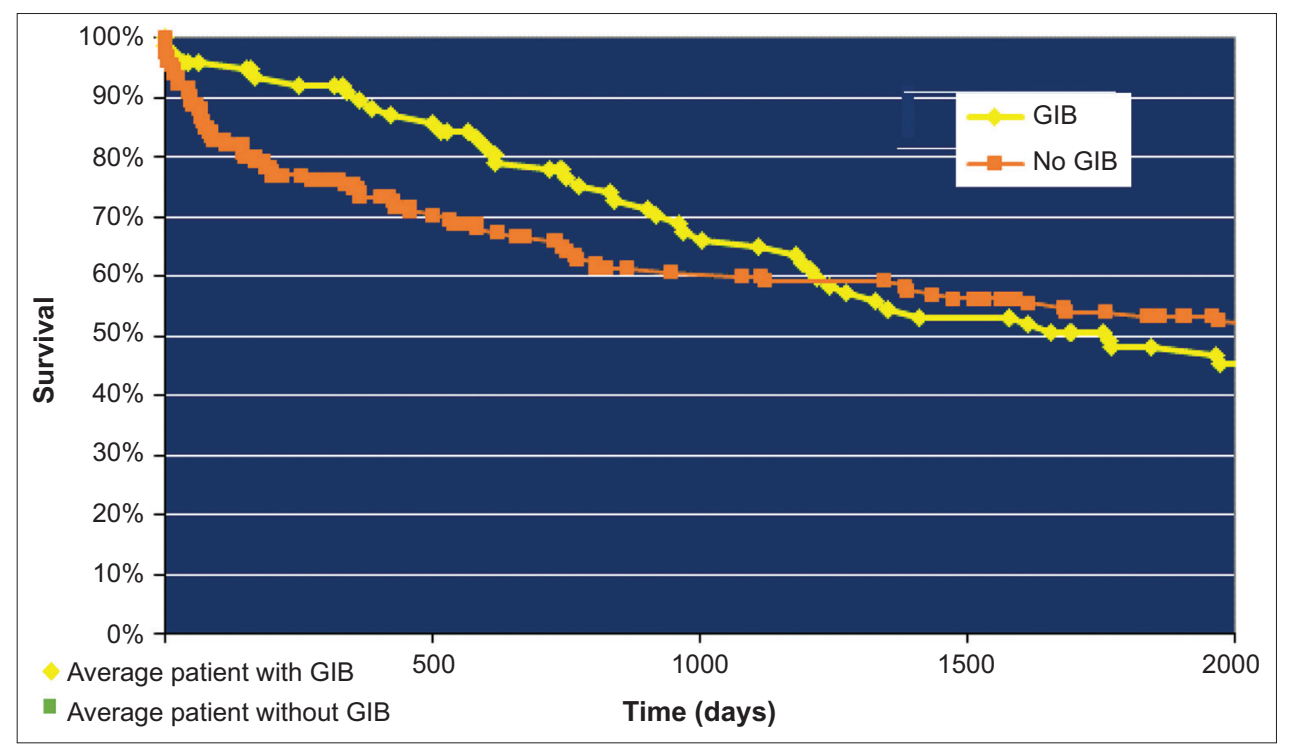

Figure 2 Actuarial Survival of GIB vs. control group GIB, gastrointestinal bleeding

non-angioectasia lesions, and location of bleeding were not statistically significant predictors of rGIB. Longer duration of hospitalization appeared to be protective for $\mathrm{rGIB}$ on univariate analysis. Previous studies reported that EGD may have the highest diagnostic yield or that early deep overtubeassisted enteroscopy may decrease the number of pRBC transfused. Since the vast majority of patients in our study did get endoscopy ( $96 \%$ ) for index GIB, it is difficult to conclude if these patients benefited. GI endoscopy is still recommended for clinically overt GIB with benefits of stopping acute bleeding and shortening hospitalization. While the ability to prevent rGIB did not exist in our study, it is difficult to determine if the predictive value of index endoscopic findings was helpful to risk stratify for future GIB. Given the predominance of angioectatic lesions, their pathophysiology, and distribution throughout the bowel, it is reasonable to hypothesize that endoscopic intervention may not be effective to decrease the risk of rGIB. For now, there does not appear to be any evidence that endoscopic management of these patients decreases the frequency of GIB or hospitalizations for GIB [18,21,30,31].

Mortality from GIB in LVAD patients has not been consistently reported in previous studies and was similar between GIB and control groups. This analysis is limited by the univariate methodology and its retrospective nature, as cohorts were not temporally matched. Interestingly, GIB tended to have a lower mortality at 1 year and this may reflect that more frequent hospitalizations increased medical optimization, which is lost over time. There has been a shift in focus on medical management on this unique population of patients [32]. There were 4 patients in our study population treated with octreotide for rGIB. Three-quarters of these patients responded to octreotide with a decreased frequency of GIB, similar to other studies. It should be noted that a small subset of LVAD patients ( $~ 5 \%)$, have refractory rGIB ( $\geq 4$ GIB events) representing a particularly morbid population that may not have been captured in our study or previous reports.
Our study is limited by being a retrospective chart review. In addition, the definition of GIB requiring hospitalization may have underestimated the true incidence of GIB and rGIB. Finally, the sample size may have not been significantly powered to identify other predictors.

This study highlights the heterogeneity and challenges in management of GIB and rGIB in LVAD patients. Shared decision making should be an important part of the discussion with patients undergoing destination therapy and or longer duration of LVAD, as these are non-modifiable risk factors. Albumin is strongly associated with the risk of index GIB and attempts should be made to focus on this parameter in the outpatient setting. While this is a retrospective, singlecenter study, endoscopic approach or intervention was not associated with the risk for rGIB. While not emphasized in the literature, this appears consistent with previously published research. Currently, there is not enough evidence to forgo endoscopy in patients with LVAD and GIB. Future prospective studies should evaluate the optimal endoscopic approach and intervention in this unique population. Medical management including non-pharmacologic and pharmacologic treatment options (e.g., thalidomide and octreotide) and novel approaches (e.g., omega-3 and angiotensin converting enzyme inhibitors/angiotensin receptor blockers) should be further evaluated [33-36].

In conclusion, destination therapy, longer duration of LVAD, and low albumin were independent predictors of index GIB in our study. In addition, endoscopy with/without intervention does not appear to affect the risk of rGIB. GIB and rGIB remain a significant comorbidity in patients with LVAD. Management remains a challenge for caregivers, is frustrating for patients, and places a significant burden on healthcare resources. Given the number of non-modifiable risk factors and heterogeneity of this population, future prospective studies should focus on exploring other treatment options for these patients. 


\section{Summary Box}

\section{What is already known:}

- Gastrointestinal bleeding (GIB) in left ventricular assist device (LVAD) patients is a major source of morbidity and challenging to treat

- Several non-modifiable risk factors have been identified

- GIB tends to occur along the entire gastrointestinal tract with angioectasia being the most common lesion identified

- There is no consensus on the optimal approach to endoscopic intervention

\section{What the new findings are:}

- Endoscopy during index GIB with or without intervention does not appear to affect the risk of recurrent GIB

- Destination therapy, longer duration of LVAD, and low albumin are predictors of index GIB

- Management of recurrent GIB in this unique population should focus on medical management

\section{References}

1. Benjamin EJ, Blaha MJ, Chiuve SE, et al. Heart disease and stroke statistics-2017 update: a report from the American Heart Association. Circulation 2017;135:e146-e603.

2. Feldmann C, Chatterjee A, Haverich A, Schmitto JD. Left ventricular assist devices - a state of the art review. Adv Exp Med Biol 2018;1067:287-294.

3. Stulak JM, Davis ME, Haglund N, et al. Adverse events in contemporary continuous-flow left ventricular assist devices: a multi-institutional comparison shows significant differences. J Thorac Cardiovasc Surg 2016;151:177-189.

4. Lopilato AC, Doligalski CT, Caldeira C. Incidence and risk factor analysis for gastrointestinal bleeding and pump thrombosis in left ventricular assist device recipients. Artif Organs 2015;39:939-944.

5. Aggarwal A, Pant R, Kumar S, et al. Incidence and management of gastrointestinal bleeding with continuous flow assist devices. Ann Thorac Surg 2012;93:1534-1540.

6. Yandrapalli S, Rochlani Y, Harikrishnan P, et al. Hospitalizations for major bleeding and outcomes in patients with ventricular assist devices. J Am Coll Cardiol 2018;71:962.

7. Imamura $T$, Kinugawa $K$, Uriel $N$. Therapeutic strategy for gastrointestinal bleeding in patients with left ventricular assist device. Circ J 2018;82:2931-2938.

8. Kim JH, Brophy DF, Shah KB. Continuous-flow left ventricular assist device-related gastrointestinal bleeding. Cardiol Clin 2018;36:519-529.

9. Kushnir VM, Sharma S, Ewald GA, et al. Evaluation of GI bleeding after implantation of left ventricular assist device. Gastrointest Endosc 2012;75:973-979.

10. Cushing K, Kushnir V. Gastrointestinal bleeding following LVAD placement from top to bottom. Dig Dis Sci 2016;61:1440-1447.

11. Singh G, Albeldawi M, Kalra SS, Mehta PP, Lopez R, Vargo
JJ. Features of patients with gastrointestinal bleeding after implantation of ventricular assist devices. Clin Gastroenterol Hepatol 2015;13:107-114.e1.

12. Harvey L, Holley CT, John R. Gastrointestinal bleed after left ventricular assist device implantation: incidence, management, and prevention. Ann Cardiothorac Surg 2014;3:475-479.

13. Kataria R, Jorde UP. Gastrointestinal bleeding during continuousflow left ventricular assist device support: state of the field. Cardiol Rev 2019;27:8-13.

14. Dakik HK, McGhan AA, Chiu ST, et al. The diagnostic yield of repeated endoscopic evaluation in patients with gastrointestinal bleeding and left ventricular assist devices. Dig Dis Sci 2016;61:1603-1610.

15. Demirozu ZT, Radovancevic R, Hochman LF, et al. Arteriovenous malformation and gastrointestinal bleeding in patients with the HeartMate II left ventricular assist device. J Heart Lung Transplant 2011;30:849-853.

16. Gurvits GE, Fradkov E. Bleeding with the artificial heart: gastrointestinal hemorrhage in CF-LVAD patients. World $J$ Gastroenterol 2017;23:3945-3953.

17. Al-Bawardy B, Schettle SD, Gorospe E, et al. Small bowel bleeding in patients with left ventricular assist device: outcomes of conservative therapy versus balloon-assisted enteroscopy. Ann Gastroenterol 2018;31:692-697.

18. Elmunzer BJ, Padhya KT, Lewis JJ, et al. Endoscopic findings and clinical outcomes in ventricular assist device recipients with gastrointestinal bleeding. Dig Dis Sci 2011;56:3241-3246.

19. Amornsawadwattana S, Nassif M, Raymer D, LaRue S, Chen CH. Video capsule endoscopy in left ventricular assist device recipients with obscure gastrointestinal bleeding. World $J$ Gastroenterol 2016;22:4559-4566.

20. Hirose H, Sarosiek K, Cavarocchi NC. Ad hoc cost analysis of the new gastrointestinal bleeding algorithm in patients with ventricular assist device. ASAIO J 2014;60:351-352.

21. Sarosiek K, Bogar L, Conn MI, O’Hare B, Hirose H, Cavarocchi NC. An old problem with a new therapy: gastrointestinal bleeding in ventricular assist device patients and deep overtube-assisted enteroscopy. ASAIO J 2013;59:384-389.

22. Charlson ME, Pompei P, Ales KL, MacKenzie CR. A new method of classifying prognostic comorbidity in longitudinal studies: development and validation. J Chronic Dis 1987;40:373-383.

23. Draper KV, Huang RJ, Gerson LB. GI bleeding in patients with continuous-flow left ventricular assist devices: a systematic review and meta-analysis. Gastrointest Endosc 2014;80:435-446.e1.

24. Albeiruti R, Chaudhary F, Alqahtani F, Kupec J, Balla S, Alkhouli $\mathrm{M}$. Incidence, predictors, and outcomes of gastrointestinal bleeding in patients admitted with ST-elevation myocardial infarction. Am J Cardiol 2019;124:343-348.

25. Welden CV, Truss W, McGwin G, Weber F, Peter S. Clinical predictors for repeat hospitalizations in left ventricular assist device (LVAD) patients with gastrointestinal bleeding. Gastroenterology Res 2018;11:100-105.

26. Yin MY, Ruckel S, Kfoury AG, et al. Novel model to predict gastrointestinal bleeding during left ventricular assist device support. Circ Heart Fail 2018;11:e005267.

27. Critsinelis AC, Kurihara C, Kawabori M, et al. Predictive value of preoperative serum albumin levels on outcomes in patients undergoing LVAD implantation. J Card Surg 2018;33:469-478.

28. Wever-Pinzon O, Selzman CH, Drakos SG, et al. Pulsatility and the risk of nonsurgical bleeding in patients supported with the continuous-flow left ventricular assist device HeartMate II. Circ Heart Fail 2013;6:517-526.

29. Thohan V, Shi Y, Rappelt M, et al. The association between novel clinical factors and gastrointestinal bleeding among patients supported with continuous-flow left ventricular assist device 
therapy. J Card Surg 2019;34:453-462.

30. Meyer MM, Young SD, Sun B, Azzouz M, Firstenberg MS. Endoscopic evaluation and management of gastrointestinal bleeding in patients with ventricular assist devices. Gastroenterol Res Pract 2012;2012:630483.

31. Truss WD, Weber F, Pamboukian SV, Tripathi A, Peter S. Early implementation of video capsule enteroscopy in patients with left ventricular assist devices and obscure gastrointestinal bleeding. ASAIO J 2016;62:40-45.

32. Molina TL, Krisl JC, Donahue KR, Varnado S. Gastrointestinal bleeding in left ventricular assist device: octreotide and other treatment modalities. ASAIO J 2018;64:433-439.

33. Ge ZZ, Chen HM, Gao YJ, et al. Efficacy of thalidomide for refractory gastrointestinal bleeding from vascular malformation.
Gastroenterology 2011;141:1629-1637.e1-e4.

34. Imamura $\mathrm{T}$, Nguyen $\mathrm{A}$, Rodgers $\mathrm{D}$, et al. Omega-3 therapy is associated with reduced gastrointestinal bleeding in patients with continuous-flow left ventricular assist device. Circ Heart Fail 2018;11:e005082.

35. Juricek C, Imamura T, Nguyen A, et al. Long-acting octreotide reduces the recurrence of gastrointestinal bleeding in patients with a continuous-flow left ventricular assist device. J Card Fail 2018;24:249-254.

36. Converse MP, Sobhanian M, Taber DJ, Houston BA, Meadows HB, Uber WE. Effect of angiotensin II inhibitors on gastrointestinal bleeding in patients with left ventricular assist devices. J Am Coll Cardiol 2019;73:1769-1778. 